\title{
infancialização, ubuntu e teko porã: elementos gerais para educação e ética afroperspectivistas
}

\author{
renato noguera ${ }^{1}$ \\ universidade federal rural do rio de janeiro, brasil \\ marcos barreto ${ }^{2}$ \\ prefeitura de japeri-rio de janeiro, brasil
}

As pessoas crescidas não compreendem nada por si
mesmas, e é trabalhoso, para as crianças, estar sempre
dando explicações.
Antoine de Saint-Exupéry

resumo

Este artigo propõe uma abordagem pouco comum sobre a infância e as dinâmicas das ações do cotidiano escolar. Partindo do pressuposto que a infância é um conceito polissêmico, convidamos à reflexão do conceito de infancialização como possibilidade de rompimento com as práticas atuais de experimentação da realidade, a partir de orientações filosóficas africanas e indígenas. Para tal, será estabelecido o diálogo com a filosofia africana Ubuntu e indígena Teko Porã com objetivo de trazer - ao âmbito educacional - as relações de construção do indivíduo na coletividade, reconhecendo e respeitando a diversidade numa visão planificada, onde os seres vivos vivem numa relação de interdependência. Tais conceitos abandonam a perspectiva colonizadora de que somos preparados para dominar, enfatizando que seres humanos, animais nãohumanos e o meio ambiente não estão à disposição e devemos tratar os seres vivos sem utilitarismo, ou seja, como parte de nós.

palavras-chave: ubuntu; teko porã; infancialização; ética.

\section{infantilization, ubuntu and teko porã: general elements for education and ethics afroperspectivistas}

abstract

This article proposes an unusual approach on childhood and the dynamics of school routine. Starting from the assumption that childhood is a polysemous concept, it invites reflection on the concept of childfication as a possibility of rupture with current practices of reality's experimentation, based on African and Brazilian indigenous philosophical frameworks. In order to do this, a dialogue is established with the African philosophy of Ubuntu and Brazilian indigenous philosophy's Teko Porã with the aim of bringing to the educational area the connection of the individual with community, recognizing and respecting diversity in a planned vision, where living beings live in an interdependent relationship. These concepts discard the colonizing perspective that we are prepared to dominate, emphasizing that human beings, nonhuman animals and the environment are not available and we must treat living beings without utilitarianism, but like a part of us.

keywords: ubuntu; teko porã; childfication; ethics

\footnotetext{
${ }^{1}$ renatonoguera@ymail.com

2 marcosriodejaneiro@gmail.com 


\section{infantilismo, ubuntu y teko porã: elementos generales para educación y ética afroperspectivistas}

resumen

Este artículo propone un abordaje poco común de la infancia y las dinámicas de las acciones de la vida escolar. Partiendo del supuesto de que la infancia es un concepto polisémico, invitamos a la reflexión sobre el concepto de infancialización como posibilidad de ruptura con las prácticas actuales de experimentación de la realidad, desde orientaciones filosóficas africanas e indígenas. Para ello, se establecerá un diálogo con la filosofía africana Ubuntu e indígena Teko Porã, con el objetivo de llevar al ámbito educativo- las relaciones de construcción del individuo en la colectividad, reconociendo y respetando la diversidad en una visión planificada, en la que los seres vivos viven en una relación de interdependencia. Estos conceptos abandonan la perspectiva colonizadora, a partir de la cual somos preparados para dominar, enfatizando que los seres humanos, animales no-humanos y el medio ambiente no están a disposición y debemos tratar a los seres vivos sin utilitarismo, como parte de nosotros.

palabras clave: ubuntu; teko porã; infancialización; ética. 
infancialização, ubuntu e teko porã: elementos gerais para educação e ética afroperspectivistas

\section{brevíssima introdução}

Diante de diversos desafios contemporâneos no campo da educação, as alternativas continuam tão vastas quanto interrogações. Queremos desenvolver dois encaminhamentos. Primeiro, este artigo defende a perspectiva geral de que a educação deve servir como um modo "de resistir ao esquecimento da infância que constitui todo ser humano" (KOHAN, 2010, p.125). Em segundo lugar, apostamos que uma ética afroperspectivista - formada pela leitura das filosofias ubuntu e teko porã - pode ser incorporada pela escola em favor do que denominamos de infancialização.

Nossa tese é simples: o que há de mais notável em educar é justamente produzir infancialização. Este conceito "infancialização" não pode ser confundido, em hipótese alguma, com infantilização. Em termos semânticos, o verbo infantilizar significa acriançar, "abebezar" e assume um sentido negativo, porque o discurso da modernidade coloca a criança como infante (NARODOWSKY, 2001). Mariano Narodowski situa o debate sobre as condições de produção do discurso moderno sobre a infância e como, nas sociedades ocidentais, o processo denominado de pedagogização da infância é responsável pela infantilização da criança. Nós podemos dizer que a infantilização da criança integra o discurso pedagógico moderno que procurou fixar determinados cânones "sobre a infância e o saber, ambos em situação escolar" (NARODWSKI, 2001, p.197). De modo que uma perspectiva psicológica passou a definir critérios de normalidade, de desenvolvimento e expectativas de rendimento, dentre outros elementos.

A infancialização parte do pressuposto afroperspectivista, a saber: a infância enquanto conceito filosófico é disruptiva. Infancializar é uma maneira de perceber na infância as condições de possibilidade de invenção de novos modos de vida. As questões gerais são: dentro do repertório afroperspectivista, quais as relações entre educação e infância? Que éticas educam a favor da infância? Enfrentaremos essas perguntas a partir de modelos filosóficos africanos e indígenas. Com um desafio básico em todo horizonte deste ensaio, a escola deve amadurecer estudantes, desenvolvê-los? Ou, seria o caso dela fazer do estudo um exercício de resistir ao esquecimento da infância?

\section{afroperspectividade: a base teórica}

A afroperspectividade é a abordagem filosófica (NOGUERA, 2011; 2014; 2015) que guia nossa fundamentação em favor da infancialização como um princípio ético. A expressão afroperspectividade é herdeira de um debate a respeito da inclusão de vozes africanas e ameríndias nas áreas de filosofia e educação. Dentre as leituras e referências que delineiam o surgimento da abordagem afroperspectivista podemos destacar, a antropóloga guarani nhandeva Sandra Benites; a antropóloga branca Tânia Stolze Lima; a socióloga nigeriana Oyeronke Oyewumi; o filósofo quilombola Antônio Bispo dos Santos; o xamã e filósofo yanomami Davi Kopenawa; o pan-africanista e sistematizador 
da afrocentricidade Molefi Asante; o cientista social e ativista negro Abdias do Nascimento; o antropólogo branco brasileiro Eduardo Viveiros de Castro e os pensadores brancos franceses Gilles Deleuze e Félix Guattari.

Em Denegrindo a filosofia: o pensamento como coreografia de conceitos afroperspectivistas encontramos as linhas mestras da afroperspectividade. Partimos da trindade filosófica deleuzeana-guattarieana: traçar um plano de imanência, inventar personagens conceituais e criar conceitos em função de um problema (DELEUZE; GUATTARI, 1992, p. 101). Nos dizeres dos pensadores franceses, o plano de imanência é uma imagem do pensamento, "um corte do caos e age como um crivo" (Idem, 1992, p. 59), um horizonte através do qual o pensar se orienta.

Nosso plano de imanência são cosmovisões africanas, afro-brasileiras e ameríndias demarcadas pela perspectiva da localização que aqui denominaremos de cosmosentidos afroperspectivistas. $O$ termo afroperspectividade emerge da leitura do quilombismo de Abdias do Nascimento (1980), da afrocentricidade sistematizada por Molefi Asante (1987) e do perspectivismo ameríndio proposto por Tania Stolze Lima (2011).

As contribuições de Tânia Stolze Lima advêm da "elaboração da teoria etnológica do perspectivismo ameríndio" (LIMA, 2011, p. 606). “A chave para a leitura do perspectivismo ameríndio está na definição da perspectividade como capacidade ou potência para ocupar outro ponto de vista" (NOGUERA, 2014, p. 49). Moelfi Asante afirma que "afrocentricidade é uma questão de localização porque os africanos vêm atuando na margem da experiência eurocêntrica" (ASANTE, 2009, p.93) e, ao mesmo tempo, visa promover a agência, isto é, carrear recursos intelectuais e políticos para emancipação dos saberes negros. A partir de Abdias do Nascimento, postulamos o "quilombismo é a espinha dorsal política que dá o sul da afroperspectividade" (NOGUERA, 2014, p.47). Por fim, afroperspectividade significa criar conceitos africanos e indígenas para enriquecer o enfrentamento de problemas que corriqueiramente são pensados por meio de ideias ocidentais. Por outro lado, isto quer dizer: tecer provocações que destaquem possibilidades que infancializar traz para a vida. Formalizamos um convite para pensarmos afroperspectivamente sobre a infância, com a infância, a partir da infância e a seu favor, ainda que para isso, seja preciso ir contra ela e boa parte do que pensávamos a seu respeito.

\section{ubuntu e infância}

"Ubuntu" não é uma palavra mágica que surge para resolver os conflitos e "salvar" as pessoas diante de disputas políticas. Ubuntu não é uma lei universal que está viva em todo continente africano. A palavra "ubuntu" não existe em todas centenas de línguas faladas nos 54 países africanos; ela está presente em quatro idiomas: Ndebele, Swati, Xhosa e Zulu. Apesar de encontrarmos palavras sinônimas em algumas línguas, - Sesotho, Shangaan, Vhuthu, Tsonga e Swahili - ubuntu é uma palavra compartilhada por quatro línguas africanas e nas sociedades falantes desses idiomas - acima mencionadas. Para falar do seu significado filosófico, ético e político, vamos contar de modo panorâmico e ligeiro a história de dois personagens históricos notáveis sul-africanos nascidos no século XX: Mandela e Desmond Tutu. 
Nelson Rolihlahla Mandela (1918-2013) e Desmond Mpilo Tutu (1931) foram vencedores do Prêmio Nobel da Paz, Mandela em 1993 e o arcebispo anglicano nove anos antes, em 1984. O termo ubuntu tornou-se muito popular depois de discursos e práticas desses dois sul-africanos serem ouvidos e reconhecidos pelo resto do mundo. Mandela, membro do clã Madiba da etnia Thembu, foi criado para assumir a liderança política do seu povo e recorreu à palavra "ubuntu" para sustentar o argumento da importância de reconhecer que o conflito faz parte das relações humanas. A partir da tese ubuntu, Mandela defendeu que a inclusão dos brancos no cenário de decisões políticas não seria exemplo de "conciliação" sem dificuldades; mas assumir politicamente a reparação em diversas áreas. Portanto Mandela propôs políticas reparatórias que faziam parte do sistema ubuntu.

No mesmo sentido, o arcebispo anglicano Desmond Tutu da etnia Xhosa fez vários discursos e escreveu um livro apelidado de "livro do perdão" junto com sua filha Mpho Tutu. Em várias ocasiões, ele aproximou "perdão" de ubuntu, o que pode ter causado interpretações controversas, porque o sentido de "perdoar" na cultura cristã ocidental está geralmente identificado com esquecer o passado e iniciar uma nova vida. Ora, Desmond Tutu disse que perdoar não significa que a vítima deva esquecer, mas ressignificar num processo que caminha junto com ações das pessoas agressoras para restituírem o mal que fizeram. Tutu dá ênfase à reparação quando faz a aproximação de "perdão" com ubuntu. A sua intenção enquanto sacerdote é vincular ubuntu com o cristianismo, politizando-o. O pensador dinamarquês Christian B.N. Gade foi muito feliz com a publicação de The Historical development of the Written Discourses on Ubuntu. Gade que faz um balanço histórico do termo ubuntu, localizando 14 textos no século XIX, tendo um primeiro publicado em 1846 (GADE, 2011, p. 306). Mas, de acordo com Gade (2011), a primeira obra em que ubuntu se tornou objeto central de estudo foi Hunhuism or Ubuntuism: A Zimbabwe Indigenous Political Philosophy de Stanlake Samkange e Tommie Marie Samkange, num estudo publicado em 1980, faz uma comparação entre a palavra do idioma Shona, "hunhu" com ubuntu, analisando como durante a transição de um governo de minoria branca para uma gestão de maioria negra, a solução dos problemas não foi baseada no capitalismo ou no socialismo; mas, na filosofia política ubuntu. O levantamento de Gade faz um bom panorama do debate em torno das posições políticas de Mandela ao assumir a presidência sul-africana em 1994. Gade ajuda a fazer um estado da arte $^{3}$ preliminar sobre o assunto, desmistificando algumas ideias que identificam ubuntu como uma saída simplista, rasa e universal para problemas profundos e complexos.

Em Filosofia Africana: ontem e hoje (1998), o filósofo Joseph Omoregbe afirma que uma maneira de fazer leituras filosóficas africanas é mergulhar em provérbios e aforismos tradicionais. Os provérbios: "umuntu ngumuntu ngabantu" e "umntu ngumntu ngabantu" são máximas ético-políticas nos idiomas isizulu e isixhosa dos povos Zulu e Xhosa (RAMOSE, 1999). A partir de diversos estudos (RAMOSE, 1999; GADE, 2011), reitera-se que uma tradução

33 Por estado da arte entendemos uma metodologia de pesquisa que faz um levantamento bibliográfico para mapear e discutir a produção acadêmica em diferentes áreas de conhecimento para enfrentar perspectivas e aspectos ao longo do tempo e em circunstâncias distintas sobre um determinado assunto. 
razoável dos dois provérbios é: "uma pessoa é pessoa através de outras pessoas". O filósofo sul-africano Mogobe Ramose tem feito tratados éticos e políticos que estão estruturados no contexto da cosmovisão cultural ubuntu. Um aspecto importante é justamente o conceito de polidiálogo. A noção de que dialogar não é um processo com objetivo final pré-estabelecido. Não raramente, a finalidade do diálogo é interpretada um tipo de resultado dialético que supera as partes anteriores. O polidiálogo é o reconhecimento de que existem pontos de vistas que são incompatíveis. Porém, precisamos enfrentar justamente esses pontos sem buscar consenso ou um equilíbrio final. Em termos ramoseanos, o que caracteriza o ser - entendido como a natureza de tudo que existe, incluindo humanos - é a instabilidade.

Incerteza, medo, alegria, tristeza, solidão, companheirismo e boa saúde, são alguns dos fenômenos que definem a instabilidade fundamental do mundo dos vivos. A pergunta é: como é que podemos responder à instabilidade fundamental de ser? $\mathrm{Na}$ filosofia ubuntu, um ser humano no mundo dos vivos deve ser um umuntu, com intenção de dar uma resposta ao desafio da instabilidade fundamental do ser (RAMOSE, 1999, p.66).

Para Ramose, a instabilidade é intrínseca à vida. Os seres humanos são desafiados constantemente a enfrentar o caráter instável da vida. Ontologia e epistemologia estão imbricadas à medida que o estudo do ser (a ontologia) não pode ser dissociada de uma investigação a respeito da validade do conhecimento (epistemologia). De modo que ontologia e epistemologia são indivisíveis (Idem, p. 52).

A hipótese ubuntu é de que a instabilidade da vida inviabiliza as soluções simplistas e gerais. Por essa razão, não devemos procurar uma alternativa universal; mas, reconhecer que a pluriversalidade - a coexistência de visões de mundo distintas e igualmente "válidas" - é uma possibilidade que retrata melhor a experiência da vida e os conflitos que enfrentamos no mundo (RAMOSE,1999; 2010; 2011).

Após essa apresentação, é preciso situar o conceito de infância no contexto cultural dos povos bantu em que existem filosofias organizadas pelo eixo central ubuntu e similares. Nós vamos nos ater ao contexto Xhosa. Uma das fontes está no livro Ndiphilile: Eu Estou Viva!, um trabalho no qual encontramos relatos de experiências e formulações teóricas a partir da vivência de uma coordenadora pedagógica de uma escola catarinense de orientação Waldorf, Sandra Eckschmidt (2016). Ela ficou de janeiro a julho de 2015 na Escola Zenzeleni em Khayelitsha a 30km da cidade de Cape Town, na África do Sul. Uma das constatações mais notáveis, que se tornou o tema central do livro, foi o tempo livre para brincar dentro da escola. O brincar livre das crianças no contexto escolar nos ajudou a pensar o caráter brincante da infância.

A partir de estudos de Zamantuli Scaraffiotti (2011), a palavra "ubuntwana"4 significa infância e "umntwana" quer dizer criança. O que chama atenção é que infância está inscrita numa hipótese que se justifica a partir do conceito de ubuntu. A princípio, ubuntwana (infância) é formada por

${ }^{4}$ Importante frisar que o termo "umntwana" significa mais exatamente "criança". 
um tipo de aglutinação entre "ubuntu" e a palavra "twana". Essa articulação ubuntu + twana é bem distinta do sentido ocidental baseado na língua latina, in + fanti. Neste último caso, "in" é um prefixo de negação e "fanti" nos remete ao verbo falar e à variante falante. Ora infância significa nesse contexto "ausência de fala". Mas, em xhosa "twana" remete para uma relação de afeto, paixão, uma inclinação enamorada e de onde o sentido de infância em xhosa remeteria para afeto enamorado pela humanidade, o que difere de amor incondicional e irrestrito. A partir de considerações ramoseanas (2010), o afeto é plural e diverso. Outra versão sobre a palavra infância em xhosa, ubuntwana, está na aglutinação de ubuntu, ou ainda do primeiro radical do termo "ubu" (ser) com "ntwana" (infância propriamente dita).

Optamos por uma variação etimológica que aparece nos estudos linguísticos de Scaraffiotti e que não entra em choque com a interpretação filosófica ramoseana. Daí ubuntwana significar justamente a relação de estar afetado pela experiência de realizar-se como humano através de vivenciar relações com outros seres humanos. Nossa interpretação é simples, o sentido filosófico da infância que está presente na palavra "ubuntwana" é notável. A infância é a condição de possibilidade de experimentação da humanidade individual através da vivência com outros seres humanos, afirmação da nossa condição de seres interdependentes. Portanto, a partir de uma análise semântica da palavra ubuntwana, a infância guarda a proximidade com o próprio sentido de ubuntu. Em contextos africanos tradicionais bantu, especificamente as tradições xhosa e zulu, ensinam algo que foi inspirador e decisivo para compor o verbo infancializar ${ }^{5}$ e reconhecer a infancialização como meta políticoeducativa estruturante de qualquer projeto que envolva aprender. No contexto ubuntu, ubuntwana quer dizer infância enquanto agente de provocação, capaz de afetar afetivamente, acolher e provocar o encantamento diante da vida. Em termos filosóficos, a infância aqui aparece como uma condição de experiência humana privilegiada. Numa interpretação afroperspectivista das considerações de Ramose e Scaraffiotti, encontramos a possibilidade de estipular infância como conceito que remete a um estado, ou ainda, uma forma de vida que torna possível assumir a instabilidade da vida radicalmente. De acordo com Ramose e Scaraffiotti, a instabilidade é inerente à existência. Porém, Ramose ressalta que a filosofia ubuntu "define a comunidade como uma entidade dinâmica com três esferas, a saber: a dos vivos, a dos mortos-vivos ('ancestrais') e a dos ainda não nascidos" (2010 a, n.p.). Neste sentido, a infância (ubuntwana) pode ser interpretada como um elo de ligação entre a ancestralidade, futuridade e viventes. Por ser justamente a presença do passado e do futuro na emergência do presente. Em outras palavras, ubuntwana é a afirmação que, para além dos cinco sentidos (visão, olfato, tato, paladar e audição), existe outro (sentido) que chamamos de infância. Um sentido que estaria mais aguçado nas crianças, mas que não é perdido pelos adultos. Infancializar é ativar a infância em adultos,

\footnotetext{
${ }^{5}$ Infancializar é um neologismo em que ressaltamos linguisticamente outros sentidos do/para o termo infância. Ao invés do "in" como prefixo de negação. Nós aqui fazemos traduções e interpretações de línguas africanas e idiomas de povos indígenas em que "infância" é uma grande potência vital de descoberta da realidade. Por exemplo, as palavras "ndaw" em wolof, "ubuntwana" em xhosa, "kyringue" em guarani e "crúc" em krenak trazem sentidos convergentes entre si, divergindo do vocábulo latino infantia - ausência da capacidade de fala.
} 
tornando viável a percepção de que as ações éticas e políticas precisam levar em conta quem já esteve aqui (ancestralidade) e quem estará (futuridade), além das pessoas que estão vivas na atualidade. Ubuntwana é assumir a infância como um sentido que propicia que encaremos a realidade como um território de contínua produção, instável e passível de reformulações e ressignificações. Por fim, ubuntwana remete, no contexto da filosofia ubuntu, a compreender a infância e, ao mesmo tempo, as crianças como inventoras de novos mundos.

\section{teko porã e infância}

Quando o assunto é infância, cabe a ressalva: "não é possível definir um modo indígena de conceber a infância, pois encontramos em populações indígenas variadas formas de tratar esse período" (TASSINARI, 2007, p.13). O que nos interessa é a infância no contexto cultural guarani de emergência do princípio filosófico e cosmo-político teko porã. No contexto guarani, "há o reconhecimento da autonomia da criança, que deve ser respeitada. A criança é vista como um ser de fato, portador de um espírito que precisa ser cativado para ficar na terra" (TASSINNARI, 2007, p.14). Outro aspecto importante, entre os Guaranis, as crianças estão próximas dos deuses (idem, p.18). Ora, isso tudo demarca uma compreensão da infância distinta daquela velha ideia ocidental, na qual a criança ocupa a categoria infância em contraposição ao adulto como fase referencial de completude e maturidade. Alguns estudos, tais como a pesquisa "Infâncias e Educação Guarani" coordenada pela psicóloga e doutora em Educação Ana Luisa Teixeira de Menezes, ajudam a fazer uma boa incursão no território da infância Guarani e articular com teko porã. Ana Luisa Menezes, em parceria com Sandra Regina Simonis Richter, escreveu: "nossa intenção de compreender a educação das infâncias a partir um modo de pensar ameríndio ignorado ou silenciado por uma história colonial de mais de quatro séculos" (MENEZES \& RICHTER, 2014, p.104). Ora, uma leitura das infâncias no contexto Guarani parte de um aspecto bastante interessante: o sonho. A educadora e antropóloga guarani Sandra Benites ensina que a educação de uma criança começa com o sonho que mãe e pai nutrem a seu respeito. "Quando uma mulher vai ter um filho ou uma filha, antes mesmo de engravidar, os pais, ou apenas um deles, sonham com o nhe'ẽ que virá" (BENITES, 2015, p.14). Ora, o sonho (xará" u) é muito importante. Afinal, "diferente de outros povos, a nossa educação começa com o sonho, com a gravidez" (BENITES, 2015, p. 22). Nossa interpretação, a infância guarani pode ser lida como o sonho vivo de realização do teko porã. À medida que toda vida começa com um sonho.

É sabido que as culturas indígenas são múltiplas. De acordo com dados do Instituto Brasileiro de Geografia e Estatística (IBGE) e do Instituto Socioambiental (ISA), no Brasil existem 305 etnias indígenas falantes de 274 línguas diferentes. A expressão "teko porã" problematiza um dilema criado pelas culturas colonização: viver à parte da terra, controlando a natureza como suprassumo da própria natureza versus viver como parte da terra, convivendo com outros seres enquanto mais um ente da natureza. Teko porã existe no tronco linguístico Guarani. É importante situar que guaranis são um conjunto de povos que vivem em regiões da Argentina, Bolívia, Brasil e Paraguai. Mbya; Pãi-Tavyterã (conhecidos no Brasil como Kaiowá); Avá Guarani (denominados 
no Brasil Nhandeva) são alguns dos diversos povos guaranis que compartilham a filosofia do "bem-viver".

Tal como ubuntu tem correlatos em outras línguas africanas. O teko porã tem "sinônimos" em Quíchua, sumak kawsay e em Aymará: suma qamaña. Para adentrarmos com alguma profundidade sobre o sentido de teko porã vamos estabelecer algumas analogias. O teólogo italiano Quinto Regazzoni (2016) procurou decifrar a filosofia do bem-viver do povo Quíchua - sumak kawsay, destacando quatro dimensões: social, econômica, cultural e religiosatranscendental. Na primeira fica ressaltada a reciprocidade para o bem-estar compartilhado. Na dimensão econômica não podemos pensar em termos de desenvolvimento a partir da exploração dos recursos naturais, nesse aspecto teko porã propõe um contexto de convivência entre animais e meio ambiente, as coisas da natureza não existem para exploração; mas, para uso conforme necessidades. A dimensão cultural ressalta a pluralidade. Em seu último aspecto ficam ressaltadas questões que visem aumento do nível de vida em critérios ecológicos.

O indígena Aymará Simón Yampara (2010) dá uma bela contribuição para a discussão. Yampara critica o monopensamento ocidental, propondo uma cosmogonia ecobiótica que está na estrutura do pensamento Suma Qamaña, correlato Aymará do teko porã Guarani. Em que consiste essa cosmogonia ecobiótica? Trata-se de uma filosofia em que a cosmologia, ecologia e a análise do lugar dos seres vivos mantém-se num mesmo plano. $\mathrm{O}$ cosmos, o meio ambiente e os seres vivos são interdependentes. Neste sentido, teko porã rivaliza com a noção ocidental de que a espécie humana é a mais preparada para conhecer e dominar a "natureza". A cosmogonia ecobiótica está a nos dizer que natureza não é um "outro" à disposição do ser humano para ter seus recursos naturais explorados em função de seres "naturalmente superiores". Em outros termos, universo, sistema ecológico não são coisas; mas, seres vivos. Teko porã é um sistema filosófico que ensina: nunca trate seres vivos como se fossem coisas.

Teko porã é configurado por um quadro de virtudes, sobretudo sociais, mas que regem também os comportamentos individuais. São sobretudo sociais as virtudes que incluem a reciprocidade (expressa pelo Guarani no afixo jo que indica relação mútua): teko joja (igualdade), teko joayhu (amor mútuo). Há virtudes individuais que recebem uma qualificação que quase poderíamos chamar de climática e ambiental, como o tekoñomboro`y (estado de ser refrigério, modo de ser aprazível, tendo seus contrários qualificações compostas com tata (fogo). (MELIÁ, 2010, p. 38)

Teko porã não é uma panaceia salvadora. Mas, um projeto político, um conjunto de vivências em que as correlações de força entre cosmos, meio ambiente e outros animais, incluindo os humanos, são levadas em consideração para ações de um povo e de indivíduos. Nossa interpretação afroperspectivista considerar que se deve ter um espírito infantil para assumir que independente do meio ambiente, o bem viver é improvável. Por isso, teko porã "impõe" um Nhanderekó (modo de ser, jeito íntimo de ser e agir, isto é, uma vivência). Numa abordagem afroperspectivista, consideramos essa vivência como uma 
maneira infantil de estar no mundo. À medida que estabelece uma relação de dependência com o meio ambiente. Nós interpretamos o bem viver como sendo uma maneira de ser criança para assumir que a espécie humana precisa ser cuidada pela natureza, alvo de orientação e sujeito de atenção por parte do meio em que vive. Em outras palavras, a natureza se torna sujeito ético-político, o que estabelece um status para o meio ambiente e outras espécies de atores ético-políticos. Daí, a infância impor o Nhanderekó que se torna base das relações éticas: a percepção de que não existe diferença no contexto moderno ocidental, a criança, assim como a infância, foi designada como sinônimo de irracional, imatura, incompetente, imoral, improdutiva etc. Esses adjetivos, etimologicamente formados pelo prefixo da negação, nomeiam essa categoria social: in-fância = aquela pessoa que ainda não fala. Duas palavras guaranis circunscrevem "criança", "crianças" e "infância": mitã (crianças pequenas até aproximadamente dois ou três anos) e kyringue - crianças até 12 ou 13 anos, porque meninos deixam de ser crianças quando engrossam a voz e as meninas quando menstruam (BENITES, 2018, p. 108). De qualquer modo, Infância aqui não tem o mesmo sentido dado à categoria no contexto ocidental. A relação entre pessoas adultas e crianças difere bastante. A base cultural Guarani não trata as crianças como seres que precisem ser tutelados constantemente. Essa afirmação está baseada em diversos estudos, tais como o da pesquisadora Maria Aparecida Bergamaschi.

Registrei, no Diário de Campo (08/04/04), que "os adultos são muito atentos ao comportamento de cada criança, e esse comportamento não é questionado, mas aceito. Por isso, vê-se pouca repressão às crianças, mas um acompanhamento constante, sem julgamento moral". Essa perspectiva de não criar determinadas expectativas no modo de agir das crianças marca a fluência das relações com os adultos. (BERGAMASCHI, 2008, p. 241)

Os resultados da vivência de Aparecida Bergamaschi em três aldeias no Rio Grande do Sul nos anos de 2004 e 2005 convergem com várias análises da investigação de Alzira Lobo de Arruda Campos, Maria Helena Scalabrin C. Gomes e Marília Gomes Ghizzi Godoy em três aldeias na cidade de São Paulo. As crianças não são repreendidas, vivem o cotidiano com um grau de autonomia sem par nas sociedades urbanas do mundo branco. Nossa hipótese afroperspectivista, as crianças precisam experimentar a vivência infantil de proximidade com outros sujeitos morais não-humanos, tais como as plantas, vegetação, diversos animais de outras espécies que dividem o bioma. De modo que possam ter o que aqui denominamos de "experianças" (experiências + crianças) que são condições de possibilidade da infancialização. Em termos afroperspectivistas, especulamos que experianças remetem a abertura de dialogar com coisas animadas de outras espécies e seres inanimados. No contexto Guarani, a infância permite justamente uma politização da natureza e uma naturalização da política. O que podemos descrever como um modo de tomar a natureza como um sujeito, uma perspectiva que faz par com o entendimento de que a política não é uma invenção humana; mas, um sistema dinâmico intrínseco aos ciclos ambientais, climáticos e inúmeros fenômenos 
naturais (KOPENAWA \& ALBERT, 2015). Uma compreensão que pode ser resumida na ideia simples de que as pessoas humanas devem se entender como crianças para assumir que a natureza tem sempre algo a dize. Ou seja, a natureza é uma interlocutora com "agenda" própria. Um rio tem seu próprio curso, a mandioca tem um período para colheita, existe uma época em que se recomenda não pescar. A filosofia teko porã ensina que durante a infância que se aprende que não estamos distantes de outros seres sensíveis e podemos conversar com cada um deles. De acordo com Benites, dentro dos contextos guaranis, as crianças descobrem que não estão filiadas apenas aos seus parentes humanos. Mas, fazem parte de uma realidade mais vasta que inclui outros animais, vegetação, rios, estrelas, sol, lua, etc. Afirmar a proximidade das crianças em relação às forças divinas quer dizer justamente que elas estão numa dimensão que não as separa radicalmente do mundo natural. Natureza e cultura não estão cindidas nisso que chamamos de condição de infância. Por fim, mitã e kyringue, no contexto da filosofia teko porã, nos convidam a compreender a infância e, ao mesmo tempo, as crianças como inventoras de novos mundos. Principalmente, porque a infância é a retomada da importância de tomar a natureza como um sujeito ético.

\section{éticas}

No mundo ocidental contemporâneo, quando o assunto é ética, nós temos duas escolas que se tornaram mais influentes: o pensamento de Immanuel Kant (1724-1804) e a tradição filosófica utilitarista que tem expoentes filósofos britânicos Jeremy Bentham (1748-1832) e John Stuart Mill (1806-1873). A ética kantiana tem sido classificada como sendo deontológica, isto é, baseada em princípios e normas. Kant estabelece o imperativo categórico como o único critério válido universalmente, isto é, a obrigação moral absoluta. O dever moral que todos os seres racionais devem obedecer. A filosofia Kant compreende os seres humanos como entes racionais. Em virtude disso, o uso livre da razão implicaria necessariamente na obediência formal de leis universais. Ou seja, para Kant, o uso adequado da razão faz com que todos sejam seres éticos.

Por outro lado, o utilitarismo opera a partir de um pressuposto em que bem-estar e mal-estar, originalmente descritos e entendidos como "felicidade" e "sofrimento", são os guias fundamentais das ações humanas. Bentham e Mill propõem que o critério de avaliação de uma ação seja a "utilidade", isto é, o que contribui para o bem-estar coletivo. Conforme Mills, "as ações são corretas na medida em que tendem a promover a felicidade, e erradas conforme tendam a produzir o oposto da felicidade" (MILL, 2000, p.187). Por felicidade, aqui denominada de bem-estar, se entende prazer e ausência de dor. Enquanto por sofrimento ou infelicidade, aqui denominada de mal-estar, se deve entender como dor e privação do prazer. De onde se segue que, o princípio da utilidade significa que a ação dotada de "maior valor ético" é aquela que maximiza a felicidade geral e minimiza a dor. A ética utilitarista propõe um tipo de "equação moral". O cálculo deve considerar a maximização do bem-estar coletivo. 
Numa ligeira comparação, na ética kantiana: uma ação moral tem que poder ser universalizada. Portanto, se é inviável que todas as pessoas mintam regularmente e matar se torne uma regra de resolução das divergências - essas ações não podem ser tomadas como éticas. A argumentação kantiana é sobre os princípios, ficando estabelecido que "mentir" e "matar" não são ações éticas. Em nenhuma hipótese devemos agir mentindo ou matando.

Tomemos, por exemplo, o ato de matar um homem, um ato na sua pura materialidade. Este ato não tem nenhuma tonalidade moral própria. Pode ser um ato criminoso, se for um assassinato por interesse; um ato neutro, se for executado em legítima defesa; um ato aprovado, quando se destina a proteger a pátria. Assim, não é a materialidade que caracteriza a ação moral, mas a intenção, o princípio moral que a inspira. (FERRO \& TAVARES, 1995, p.74)

A ética kantiana se apoia nas intenções e nos princípios, a materialidade das ações fica em segundo plano quando se tratar de determinar o caráter moral. O agente moral tem que fazer por dever e não por temer as consequências. Se uma pessoa não rouba somente porque teme a prisão, a sua ação não é por dever, isto é, não tem princípio ético. Porque em circunstâncias de provável impunidade, essa pessoa cometeria o crime de roubar. Por outro lado, para a ética utilitarista: roubar, mentir, ou até mesmo matar não são "imorais" em si. Mas, podem ser ações de valor ético desde de que contribuam para felicidade da maioria das pessoas num determinado contexto.

As posições que já estabelecemos no que tange à natureza humana, e que assumimos como fundamentos, são as seguintes: que as ações dos homens são governadas por suas vontades, e suas vontades por seus desejos; que seus desejos são direcionados ao prazer e ao alívio da dor como fins, e à riqueza e ao poder como os principais meios. (MILL, 1978, p. 69)

O desejo se orienta para o prazer e se afasta da dor, por isso o conceito de utilidade, que organiza a moralidade, estar relacionado a busca do bem-estar, da felicidade individual e nas relações de custos e benefícios que envolvem outros indivíduos.

O princípio da utilidade significa aquele princípio que aprova ou desaprova cada ação de acordo com a tendência que apresenta a aumentar ou a diminuir a felicidade daqueles cujo interesse está em jogo; ou, o que é o mesmo em outras palavras, a promover ou se opor àquela felicidade. Eu digo de toda e qualquer ação e, portanto, não somente de toda ação de um indivíduo privado, mas também de toda medida de governo. (BENTHAM. 1948, p. 2) 
Em resumo, a ética do deve preconiza obediência autônoma a princípios, ideais e normas. A decisão deve (1) respeitar prescrições e regras; (2) pensar e propor criticamente. Então, a norma é inegociável. A ética utilitarista recomenda a análise das circunstâncias, dos riscos, dos custos e benefícios. A decisão passa pela avaliação de resultados possíveis das ações e o impacto da responsabilidade por suas consequências. Por fim, a norma é "flexível".

Pois bem, baseados numa articulação entre as filosofias ubuntu e Teko porã, inspirando diversos movimentos políticos e sociais contemporâneos, elaboramos as bases para uma especulação filosófica aqui denominada de ética da infância. Quais seriam as possibilidades de constituir uma ética ancorada nas abordagens ubuntu e Teko porã? No livro Nana \& Nilo: a cidade verde (NOGUERA, 2016) encontramos uma formulação com essa intenção. O livro é uma das aventuras da dupla gêmea Nana e Nilo em companhia de Mulemba, árvore cientista e filósofa que voa através do tempo, e de um passarinho verde chamado Gino. Na trama, Nilo e sua irmã, Nana, viajam para o futuro na companhia de Alice. As três crianças conhecem mais duas crianças Kaiodê e Zahy. A menina indígena guarani Zahy ensina que Teko porã é um dos lemas da cidade. Kayodê, o garoto quilombola, explica que ubuntu está na fundação da nova cidade. Na aventura, o Rio de Janeiro passou a ser chamado de Cidade Verde depois que quilombolas e indígenas passaram a tomar conta da cidade. Neste futuro são as tecnologias indígenas e quilombolas que transformaram a cidade.

O horizonte teórico que aparece na ficção tem alguns princípios. Primeiro, um entendimento de que todos os seres são sujeitos. Em seguida, um tipo de parentesco com outros seres vivos. No caso de uma ética baseada em ubuntu e teko porã fica difícil tanto calcular bem-estar como formular uma lei geral. Nossa proposta é de uma ética infancializante. Para além da grande dicotomia contemporânea, ética da convicção versus ética da responsabilidade. Nós estamos a propor uma ética da infancialização. O que será feito apenas de maneira preliminar. Ubuntu é uma ética que parte da instabilidade, do conflito e do desentendimento como elementos que caracterizam a existência humana e se organiza em função da busca de "equilíbrio" das tensões, ou ainda, de um arranjo em que acontecimentos nefastos possam ser compensados. Teko porã é uma ética que parte da necessidade de considerar o meio ambiente como sujeito e manter relações de respeito diante de forças que escapam ao controle humano. Num ensaio especulativo filosófico afroperspectivista, postulamos a articulação entre ubuntu e teko porã como base para uma ética da infancialização.

Em que consiste uma ética da infancialização? A partir das referênciasbase: ubuntu e teko porã, nós fazemos uma composição intercultural em que propomos um polidiálogo polirracional feito sempre em contexto cosmopolítico, o que será condição de possibilidade, nunca a garantia, de uma ética pluriversal. O que só seria possível, eis nossa hipótese neste campo: a partir da infancialização coletiva e irrestrita de todos os seres de uma sociedade. Apenas pessoas infancializadas podem realizar essa tarefa ética. A objeção que aqui fazemos a maioria dos sistemas éticos é bem simples, pressupõem que a ética seja feita para adultos responsáveis. Os utilitaristas, assim como os herdeiros do sistema ético kantiano, pensam em pessoas adultas quando fazem suas formulações morais. Não se trata somente de buscar princípios, tampouco 
de perseguir o prazer e calcular o que pode ser melhor para a maioria das pessoas interessadas. Nós aqui estamos aventando possibilidades diversas, tais como: um dos maiores defeitos da democracia é de que as crianças são pessoas sem direitos políticos de formular leis e participar efetivamente. Na maioria das sociedades contemporâneas, somente adultos podem votar e ser votados ainda que adolescentes possam votar, não podem ocupar cargos legislativos, no judiciário ou no executivo. O que se dá pela desconsideração das crianças como autoras sócio-políticas. $\mathrm{O}$ que queremos ao propor uma ética da infancialização? Avançar em dois princípios: incluir as crianças no debate político e, ao mesmo tempo, convidar adultos para uma compreensão infancializada do mundo. Por outro lado, partimos dos pressupostos de que as relações não tendem ao equilíbrio.

A reconfiguração das relações políticas e sociais. Para o poeta Vicente Franz Cecim, autor de K: o escuro da semente (2016) é necessário que as crianças passem a cuidar dos adultos. Conforme Cecim, o maior desafio da escola é deslocar adultos do lugar privilegiado de fala e realocá-los como aprendizes e, ao mesmo tempo, fazer das crianças mestras. A base ética da infancialização caminha muito próxima dessa provocação política de Cecim. Ora, o poeta diz que somente quando a sociedade for governada por crianças, nós encontraremos saídas que parecem indisponíveis e que não podem ser achadas por pessoas adultas. Isso não significa que as pessoas adultas devam abandonar suas responsabilidades e sobrecarregar as crianças. Porém, reconhecer que as crianças podem estar em experianças infancializantes com mais frequências que gente adulta. $O$ que significa que educar seria colocar as infâncias em polidiálogo, propor uma conversação fértil entre diversos seres.

\section{infancialização como ética afroperspectivista: conclusões parciais...}

Numa conclusão, não podemos deixar de afirmar o óbvio, trazendo resultados que derivam da cadeia de argumentos. Em termos afroperspectivistas, a infância (ubuntwana, mitã/kyringue) é a possibilidade mais genuína da educação e o fundamento ético para conviver na instabilidade irremediável de existir. Uma maneira de intensificar a compreensão é trazendo personagens de algumas tradições religiosas como Exu e Jesus para perfazer os principais impactos da nossa tese central.

De um lado, uma história iorubá sobre o orixá Exu. De outro, uma narrativa bíblica apresentando um discurso de Jesus. A nossa intenção não é fazer incursões religiosas, tampouco considerações teológicas; mas, filosóficas. Para fazer um uso complementar que ajude leitoras e leitores a compreenderem porque a infância é uma categoria de proteção humana, do meio ambiente e capaz de produzir realidades inimagináveis. Nossa tese geral é de que a educação pode ser infancializante se for organizada dentro de princípios éticos afroperspectivistas. Vale reiterar, em termos afroperspectivistas, infancializar quer dizer: experimentar a vida de uma maneira brincante que assume a instabilidade, a impermanência e o reconhecimento de que podemos experimentar o mundo e as relações com outros seres como uma forma de autoconhecimento interdependente. Ora, essa definição pode até parecer misteriosa à primeira vista. Mas, podemos intensificar a sua compreensão 
através de interpretações afroperspectivistas de passagens religiosas com Exu (orixá iorubá) e Jesus de Nazaré, o Cristo.

Dentre as narrativas sobre Exu, destacamos uma relevante para aproximá-lo da infância (SILVA, 2015). A seu respeito é dito: foi o último orixá a ser criado. Em certa medida, um tipo de primeiro ser humano. Num verso iorubá transmitido oralmente encontramos a seguinte descrição. Iemanjá e Orunmilá tiveram quatro filhos: Ogum, Xangô, Oxóssi e Exu. Este último, o mais novo, ainda era uma criança quando os outros eram jovens. Exu nasceu e permaneceu com uma fome fora do comum. Exu comeu todos os animais da aldeia. Exu comeu os de quatro patas, os que tinham penas e asas. Exu comeu frutas, inhames, pimentas. Exu bebeu água, vinho e cerveja. Exu comia tudo que via pela frente, comia bichos, plantas, comidas frias e quentes. Exu comeu árvores, bebeu o mar e estava de olho no céu, na constelação. Orunmilá, seu pai, pediu que Ogum parasse o irmão. O mundo todo seria devorado. O orixá Ogum precisou dar cabo do irmão. Exu mesmo morto, continuava com fome. As pessoas estavam ficando sem ter o que comer. O oráculo de Ifá foi consultado e foi recomendado que antes de comer qualquer coisa, as pessoas deveriam dar os primeiros pedaços para Exu.

Pois bem, o que isso tem a ver com infância? $O$ ato de comer aqui funciona como uma metáfora da curiosidade pelo mundo. Nós interpretamos a infância como a característica da qual Exu está investido: a curiosidade por tudo que existe. A ameaça de "acabar com o mundo" indicaria tão somente, um desejo incontrolável das crianças - seres que habitam a infância por excelência em descobrir os sabores do mundo. No âmbito dos estudos psicológicos e psicanalíticos da infância encontramos várias abordagens sobre comer, morder e usos da boca. O que foi denominado por Freud como fase oral.

(...) na fase oral, a boca se constitui não somente em um órgão privilegiado de satisfação, mas principalmente em um tipo de relação entre o bebê e a mãe. Ao mamar o bebê se nutre do leite para satisfazer uma necessidade orgânica, mas principalmente para se alimentar do olhar, da voz, do amor da mãe. (ZORNIG, 2008, p.76)

Para Freud, a fase oral expressa uma dimensão muito importante da vida da criança em geral, porque assume a tensão entre existir e a aniquilação. A boca se transforma na ferramenta de manutenção da vida. Portanto, em nossa interpretação, Exu é um tipo de afirmação da infância entendida como a perspectiva de que há "equivalência entre alimento e amor materno" (Ibidem). Numa interpretação de que o "amor materno" é a condição de possibilidade de manter a criança viva. Por isso, Exu come tudo, usa a boca para manter-se em existência. Infância está a dizer que só existimos numa relação de abertura incondicional para o mundo exterior, reconhecendo-o não como rival ou adversário. Mas, com aquilo que aqui denominamos pelo neologismo de "mundofilia". A narrativa de Exu ensina que a infância é mundofílica, parafraseando o filósofo alemão Martin Heidegger (2011) que criticava gente "pobre de mundo". Aqui elogiamos a necessidade de nos movimentarmos em busca de um enriquecimento de mundos. Em outras palavras, a dinâmica exuística é infancializante. 
Em paralelo, vale destacar uma narrativa judaico-cristã que guarda muitas semelhanças com o sentido infancializante de Exu. A passagem bíblica que nos interessa é a seguinte Mateus 18, 1-6:

1. Naquele momento os discípulos chegaram perto de Jesus e perguntaram:

- Quem é o mais importante no Reino do Céu?

2. Jesus chamou uma criança, colocou-a na frente deles

3. e disse:

- Eu afirmo a vocês que isto é verdade: se vocês não mudarem de vida e não ficarem iguais às crianças, nunca entrarão no Reino do Céu.

4. A pessoa mais importante no Reino do Céu é aquela que se humilha e fica igual a esta criança.

5. E aquele que, por ser meu seguidor, receber uma criança como esta estará recebendo a mim.

6 - Quanto a estes pequeninos que creem em mim, se alguém for culpado de um deles me abandonar, seria melhor para essa pessoa que ela fosse jogada no lugar mais fundo do mar, com uma pedra grande amarrada no pescoço (BÍBLIA, Mateus 18, 1-6).

A mensagem é bem direta, a alternativa suprema aos desafios humanos só pode ser resolvida quando todas as pessoas forem crianças. Nós interpretamos que o sentido de criança esteja vinculado a uma condição explicitamente tomada como superior. A infância entendida como estado de criança indica o seguinte: um mundo melhor só é possível formado por crianças. Porque ser criança significa ser uma pessoa investida da capacidade de estar aprendendo. Criança aqui não significa apenas literalmente indivíduos de 0 a 12 anos - considerando a normatividade legal brasileira. "Criança" se aproxima de infância como conceito filosófico. Para a finalidade deste trabalho, o Reino dos Céus não será alvo de conjecturas teológicas; mas, indicado simplesmente como uma sociedade marcada pelo reconhecimento de todos viventes como sujeitos políticos, assumindo o caráter inspirador de contextos instáveis e de desentendimento. Dito isso, as pessoas investidas de infância são capazes de recusar desejo de dominação e exploração. Isso não faz da infância, é pureza ou ausência de ambivalências. Mas, assumir a interdependência em relação aos outros seres. Infância é aceitar que precisamos de cuidado contínuo de outros, recusa da empáfia advinda da crença de que somos capazes de controlar a vida. Infância é assumir que existir é marcado pelo imponderável. Toda tecnologia e conhecimento não podem garantir defesa contra meteoros, catástrofes ambientais, acidentes pessoais, etc. Infância é assumir que somos pequenos diante dos diversos desafios de existir. Infância aqui remete a incertezas naturais, ao reconhecimento de que nosso conhecimento é limitado. O fim da presunção de que temos respostas para tudo. Infancializar é justamente assumir que um mundo de bem-estar coletivo começa com o reconhecimento de que não somos capazes de obter todas as respostas diante de todos os desafios e nenhuma tradição pode ser fiadora das respostas mais "profundas". Em outros termos, "infância é a experiência de percorrer caminhos" (NOGUERA, 2017a, p.365) percebidos por sentidos potentes que 
enxergam, ouvem, tateiam, saboreiam e percebem odores que não estão disponíveis ordinariamente. Portanto, cabe aqui afirmar que infancializar é tomar a infância como experiência, ou ainda, um tipo de potência criativa para estabelecer relação como mundo. "(...) ao se tomar a infância como experiência, há que extrair de si próprio, em qualquer idade, a criança" (ABRAMOWICZ \& CRUZ 2015, p. 167). Isso, porque tomamos criança em seu sentido mais óbvio, alguém que cria e inventa porque desconhece o mundo e não acredita que precisa se dobrar a sua "objetividade".

Dito isso, a partir das narrativas judaico-cristã e iorubá, o que podemos inferir? Podemos dizer que infancializar é resultado de uma encruzilhada em que tudo corrobora para encarar a existência como um fantástico mistério. A "infância é o nome de um milagre, o da interrupção do ser das coisas pela entrada de seu outro, do outro do ser, a condição de toda e qualquer diferença" (KOHAN, 2010, p. 225). O que isso quer dizer? Somente através da infância podemos experimentar uma compreensão plural de que a vida é uma dádiva, e, diante do presente do mundo, podemos fazer da realidade uma apoteose brincante. Uma apoteose onde a rede de conversação envolve seres humanos futuros e passados, outros viventes das mais diversas espécies e todas as coisas que compõem a natureza, inclusive seres inanimados. Trata-se de uma ética em que a condição de sujeito se estende a ancestralidade, futuridade, seres vivos não-humanos e tudo que existe.

Esse tipo de ética viabiliza a infancialização como objetivo geral da escola, o horizonte da educação. Os enunciados morais afroperspectivistas que problematizam as práticas corriqueiras precisam reinventar a vida e intervir em tudo que somos no momento presente. Dentro das considerações feitas no artigo Pinóquio e Kiriku: infância(s) e educação nas filosofias de Kant e Ramose (NOGUERA, 2017b), para fins didáticos podemos situar os objetivos gerais da educação em dois grandes grupos: $1^{\mathrm{a}}$ ) Educação como um projeto de emancipação e desenvolvimento - aqui em alusão à filosofia de Kant de "maioridade da razão". 2a) Educação como um processo de preservação da memória, restauração e invenção de caminhos - infancialização.

Nós aqui optamos pela infancialização. Só se educa para mantermos a infância viva. Se o avanço e o desenvolvimento se assemelham aquilo que evolucionistas darwinistas e estudiosos kantianos insistem em definir como uma teleologia de um futuro melhor. Nós optamos pelo presente possível, pela utopia do aqui agora, ao invés da "velha" utopia futurista de que o "amanhã será melhor" e devemos nos esforçar para crescer; preferimos nos manter "crianças". Os argumentos kantianos definem a infância pelos desejos, inclinações e vontade arbitrária. "Assim sendo, a função da pedagogia estaria em emancipar, isto é, retirar a criança da condição de heteronomia e promover a sua autonomia" (NOGUERA, 2017b, p.12). Aqui estamos diante do que definimos como paradigma do desenvolvimentismo, do avanço e da maturidade da razão. O que fica subsumido sobre o termo "adultidade" neologismo criado por uma criança durante pesquisa de campo em 20176. A

\footnotetext{
${ }^{6}$ Durante pesquisa piloto de campo feita na Escola SESI de Duque de Caxias-RJ nos dias 30 de novembro de 2017; 05, 11 e 13 de dezembro de 2017. A estudante Olivia Griot Silva Nogueira, então contava com oito anos completos e cursava o $3^{\circ}$ ano do Ensino Fundamental, usou o
} 
adultidade é o conceito representante de tudo que objetamos, a nossa rival teórica. Logo, optamos por um tipo de anti-evolucionismo, antidesenvolvimentismo que não são contra a tecnologia e conquistas científicas. Mas, adversários de uma crença baseada na adultidade de que o avanço é uma panaceia salvadora. Só poderemos nos educar para vivências notáveis quando formos capazes de lembrarmos da nossa infância. Tal como nos diz o poeta brasileiro Vicente Franz Cecim nascido e criado na floresta amazônica do Estado Pará, "a infância é o que existe de mais antigo em todos nós" 7 . O que só seria viável a partir da promoção da infância como um conceito filosófico que nos dar a conhecer dimensões importantes da vida. A nossa hipótese é bastante simples: a memória só é possível na condição de infância. O que torna viável a concomitância entre restaurar caminhos e inventá-los para vivências importantes. Pois bem, o que à primeira vista pode até parecer confuso. Ora, estamos a dizer que através de vivências baseadas numa ética afroperspectivista (articulação entre princípios ubuntu e teko porã) na escola: crianças, adolescentes, adultos e idosos podem manter conexão ou se reaproximar daquilo que os torna seres biocêntricos, curiosos e criativos: a infância. Uma cumplicidade cosmológica com o existir. A escola pode primar por uma ética que não permita que as crianças deixem de habitar a infância, fazendo o mesmo com adolescentes e jovens - evitando as angústias perversas da adultidade. Óbvio que isso tudo é mais político e existencial do que psicológico. O que poderia ser resumido numa única frase-resposta, atualmente um enunciado-clichê que tem circulado intensamente nos mais diversos circuitos sociais: "quando eu crescer, quero ser infância, a mesma (infância) que fui no futuro, assim como serei criança no passado".

\section{referências}

ABRAMOWICZ, Anete; CRUZ, Ana Cristina Juvenal da. “Cartografias em Educação Infantil: o espaço de diáspora" In FARIA, Ana Lúcia; BARREIRO, Alex; MACEDO; Eliana; SANTIAGO, Flávio; SANTOS, Solange (Organizadores). Infâncias e pós-colonialismo: pesquisas em busca de pedagogias descolonizadoras. Campinas, SP: Leitura Crítica; Associação de Leitura do Brasil - ALB, 2015, pp.155-179

ASANTE, Molefi. "Afrocentricidade: notas sobre uma posição disciplinar". In NASCIMENTO, Elisa Larkin. Afrocentricidade: uma abordagem epistemológica inovadora. Tradução Carlos Alberto Medeiros. São Paulo: Selo Negro, 2009, p. 93110.

BENITES, Sandra. “Nhe'ẽ, reko porã rã: nhemboea oexakarẽ Fundamento da pessoa guarani, nosso bem-estar futuro (educação tradicional): o olhar distorcido da

termo "adultidade" para descrever o poder que as pessoas adultas tinham sobre as crianças, a estudante problematizava, porque adultos têm mais direitos do que as crianças.

7 De 28 a 31 de agosto de 2017, por ocasião do evento II Congresso Métodos Fronteiriços realizado na Universidade Federal de Rondônia (UNIR), tive a oportunidade de conhecer pessoalmente o poeta Vicente Cecim, autor do livro O escuro da semente. Durante conversa de almoço, Cecim disse esta frase, "a infância é o que existe de mais antigo em todos nós" , e autorizou o seu registro para citações. 
escola". Trabalho de Conclusão de Curso da Licenciatura Intercultural Indígena do Sul da Mata Atlântica da Universidade Federal de Santa Catarina (UFSC). Florianópolis: 2015.

. "Ore Arandu (nosso conhecimento guarani): sobre Nheê - espirito-nome" IN Revista Jesus Histórico XI, 20, 2018, pp. 104-121.

BENTHAM, Jeremy. "An introduction to the principles of morals and legislation". In: The principles of morals and legislation, Nova York, Hafner Press, 1948.

BERGAMASCHI, Maria Aparecida. "Infância nas aldeias Guarani: um modo próprio de estar dos Kyringue" Contexto E Educação. Unijuí: Editora Unijuí, a. 23 n. 79 Jan./Jun. 2008, pp.223-247.

BÍBLIA. Português. Bíblia de Referência Thompson. Trad. de João Ferreira de Almeida. Edição rev. e corr. Compilado e redigido por Frank Charles Thompson. São Paulo: Vida, 1992.

CAMPOS, Alzira Lobo de Arruda; GOMES, Maria Helena Scalabrin C.; GODOY, Marília Gomes. "Representações míticas e produção de conhecimentos: a criança (Kyringue) Guarani Mbya e os CECIs" Educação \& Linguagem, v. 19, n. 2, jul.-dez. 2016, pp. 41-62.

CASTRO, Eduardo Viveiros de. A inconstância da alma selvagem e outros ensaios de antropologia. São Paulo: Cosac \& Naify, 2002.

CECIM, Victor Franz. K: o escuro da semente. Taubáte-SP: Letra Selvagem, 2016.

DELEUZE, Gilles; GUATTARI, Félix. O que é a filosofia? Tradução Bento Prado Jr. e Alberto Alonso Munoz. Rio de Janeiro: Editora 34, 1992.

ECKSCHMIDT, Sandra. Ndiphilile: eu estou viva!; São Paulo: Ecos Livro, 2016.

FERRO, Mario; TAVARES, Manuel. Análise da obra Fundamentação da Metafísica dos Costumes de Kant. Lisboa, Univ. de Lisboa, 1995.

GADE, Christian. "The historical Development of the written Discourses on Ubuntu". South African Journal of Philosophy, 2011, pp. 303-329.

HEIDEGGER, Martin. Conceitos fundamentais da metafísica: mundo-finitude-solidão. Tradução Marco Antônio Casanova. Rio de Janeiro: Forense Universitária, 2011.

KOHAN, Walter. "Vida e Morte da Infância, entre o humano e o inumano". Educ. Real. Porto Alegre, v. 35, n. 3, set./dez., 2010, pp.125-137.

KOPENAWA, Davi; ALBERT, Bruce. A queda do céu: palavras de um xamã yanomami. São Paulo: Companhia das Letras, 2015.

LIMA, Tânia Stolze. "Por uma cartografia do poder e da diferença nas cosmopolíticas ameríndias". Revista de Antropologia, São Paulo, USP, 2011, v. 54, n. 2, pp.601-646.

MAZZA, Viviane. O menino Nelson Mandela. Ilustração: Mauricio Negro, Paolo D'altan. São Paulo: Melhoramentos, 2017.

MENEZES, Ana Luisa; RICHTER, Sandra Regina. “Infância e educação guarani: para não esquecer a palavra". Tellus, a. 14, n. 26, jan./jun. 2014, pp. 101-118.

MILL, James. "Essay on government", in R. Lively e J. Rees (eds.), Utilitarian logic and politics., Oxford: Clarendon Press, 1978.

MILL, Stuart John. Utilitarismo. Trad. Eunice Ostrensky. São Paulo: Martins Fontes, 2000.

NARODOWSKI, Mariano. Infância e poder: conformação da pedagogia moderna. $1^{\text {a }}$ Ediç ão. Bragança Paulista: Editora da Universidade de São Francisco, 2001.

NASCIMENTO, Abdias. Quilombismo: documentos de uma militância pan-africanista. Petrópolis: Vozes, 1980.

NOGUERA, Renato. "Denegrindo a filosofia: o pensamento como coreografia de conceitos afroperspectivistas". Griot. Revista de Filosofia, Amargosa, BA, v.4, n.2, dezembro/2011, pp. 1-19. 
Ensino de Filosofia e a Lei 10639. Rio de Janeiro: Pallas/Biblioteca Nacional, 2014.

"Sambando para não sambar: afroperspectivas filosóficas sobra a musicidade do samba e a origem da filosofia" In SILVA, Wallace (organizador). Sambo, logo penso: afroperspectivas para pensar o samba. Rio de Janeiro:

Héxis/Biblioteca Nacional, 2015, pp.31-55. . Nana \& Nilo na Cidade Verde. Rio de Janeiro: Chave, 2016.

"Kiriku: heterônimo da infância como experiência e da experiência da infância" In: Anais do Congresso de Estudos da Infância. Rio de Janeiro, 2017a, pp.363-370.

"Pinóquio e Kiriku: infância(s) e educação nas filosofias de Kant e Ramose". Revista AÚ, a. 02, 2017b, pp.5-18.

. "Entre a linha e a roda: infância e educação das relações étnico-raciais". Magistro Revista do Programa de Pós-Graduação em Humanidades, Culturas e Artes UNIGRANRIO, Rio de Janeiro, v.1, n.15, p. 398-419, 2017.

NOGUERA, Renato; GUTMAN, Catia; FEITOSA, Dayane. "Pintando e desenhando Pinóquio e Kiriku na escola" Aprender: caderno de Filosofia e Psicologia da Educação. Vitória da Conquista-BA, a. XI, n. 19, jul./dez. 2017, pp. 75-94.

OMOREGBE, Joseph. "African Philosophy : Yesterday and Today" In: CHUKWUDI, Eze Emmanuel. African Philosophy: an Anthology. Massachusetts/Oxford: Blacwell Publishers,1998, pp.77-98

PLATÃO. Íon. Tradução Claudio Oliveira. Belo Horizonte: Autêntica, 2011.

RAMOSE, Mogobe. “A importância vital do 'Nós'” In: Revista Instituto Humanitas Unisinos, Entrevista de Moisés Sbardelotto/Tradução Luís Marcos Sander. Edição 353, 06 de dezembro de 2010 a. Acessado em 15 de dezembro de 2011. http://www.ihuonline.unisinos.br/artigo/3688-mogobe-ramose

RAMOSE, Mogobe. “A legitimidade da filosofia africana" Ensaios. Uerj, 2011, p. 09-25. . "The death of democracy and the resurrection of timocracy". Journal of Moral Education, 2010 b, v. 39, n. 3, p. 291-303.

REGAZZONI, Quinto. “A relação entre o Reino pregado por Jesus e o conceito de Vida Boa dos povos indígenas". Revista do Instituto Humanitas Unisinos. Tradução Moisés Sbardelotto. São Leopoldo, 23 de Agosto de 2010, Edição 340, pp.14-18.

SANTOS, Antônio Bispo. Colonização, Quilombos. Modos e Significações. Brasília: Instituto de Inclusão no Ensino Superior e na Pesquisa, 2015.

SCARAFFIOTTI, Zamantuli. Parlos Xhosa: Afrique du Sud. Paris: L' Harmattan, 2011.

SILVA, Vagner Gonçalves. Exu: o guardião da casa do futuro. Rio de Janeiro: Editora Pallas, 2015.

TASSINARI, Antonella. “a”. Tellus, a. 7, n. 13, p. 11-25, out. 2007.

YAMPARA, Simón. "O bem-viver como perspectiva ecobiótica e cosmogônica" Revista do Instituto Humanitas Unisinos. Tradução Moisés Sbardelotto. São Leopoldo, 23 de agosto de 2010, Edição 340, pp.19-21.

ZORNIG, Silvia Maria Abu-Jamra. "As teorias sexuais infantis na atualidade: algumas reflexões". Psicologia em Estudo, Maringá, v. 13, n. 1, jan./mar. 2008, p. 73-77.

recebido em: 22.07 .2018

aprovado em: 05.09.2018 